\title{
Security constrained optimal power flow by modern optimization tools
}

\author{
Reham H. Salem', M. Ezzat Abdelrahman², Almoataz Y. Abdelaziz ${ }^{2 *}$ \\ ${ }^{I}$ Department of Electrical Engineering, Higher Institute for Engineering and Technology, $5^{\text {th }}$ Settlement, Cairo, EGYPT \\ ${ }^{2}$ Department of Electrical Power and Machines, Faculty of engineering, Ain shams University, Cairo,EGYPT \\ "Corresponding Author: e-mail: almoatazabdelaziz@hotmail.com
}

\begin{abstract}
In this paper, two approaches are studied for scheduling the power generators of the least cost. This is called security constrained optimal power flow [SCOPF]. This problem is represented as a two stage, security constrained OPF problem, in which the first stage optimizes the problem using a genetic algorithm for the purpose of comparison, while the second stage optimize the problem of each contingency using flower pollination algorithms (FPA) as a new trend. Case studies based on IEEE 30 bus system show that the discussed techniques are advantageous and can guarantee operational reliability and economy.
\end{abstract}

Keywords: Optimal power flow, security, genetic algorithm, flower pollination algorithm

DOI: http://dx.doi.org/10.4314/ijest.v9i3.3

\section{Introduction}

The faults and disturbances can cause unexpected outages in any power system. These are called contingencies which may lead to significant overloading with power system elements. The essential role of power system control is to keep any power system in secure state or to prevent the power system moving into emergency state at all operating conditions and this will improve the security of the system (Alsac and Scott,1973; Mithun et al., 2010). The main objective of an optimal power flow (OPF) functions is to optimize this function which is subjected to some constraints. These constraints are divided into equality constraints as power balance equations and inequality constraints as the breaking points of control factors (Gaing and Chang,2006). Some control measures should be done to keep the power system secure at the minimum cost to achieve the Security Constraint Optimal Power Flow (NIU and WAN, 2014).An answer of OPF problem can improve a particular target in working the power system by maximizing or minimizing concerning distinctive imperatives. Security constrained optimal power flow includes also outages of transmission lines and equipment.To get faster solutions, more effort should be done due to the complexity of the problem. Considerable measures of old strategies have been used as a part of understanding it.

These include the linear programming (Lima et al., 2003; Tuaimah and Meteb,2014), gradient method (Salgado et al., 2002), interior point (IP) method (Capitanescua and Wehenkel, 2013) and Newton method (Tinneyand Hart, 1967). The inequality constraints add complexity in dealing with gradient and Newton methods. The objective function is to be represented by linear equations and this lead to loss of accuracy in linear programming method. Recently global optimization strategies such as the genetic algorithm (Paranjothi and Anburaja,2002; Singh and Verma, 2012), particle swarm (Turkay and Cabadag,2013), tabu search (Abido, 2002a) and harmony search algorithm (HSA)(Sivasubramani and Swarup, 2011) have been utilized to solve the optimal power flow problem. Walters and Sheble (1993) presented an enhanced GA based OPF strategy with the individual made of paired control factors to enhance the framework security. Abido (2002b) presented the use of a PSO-based OPF technique with the individual of constant control factors structure for tackling the OPF issue with the smooth fuel cost of generator. In this paper, two optimization techniques are introduced for solving the obliged OPF problems, genetic algorithm, and flower pollination algorithm (FPA). In the discussed methods, the characteristics of the techniques and purpose are introduced in detail. The viability of the examined strategies is shown for the IEEE 30-bus system. 


\section{Problem Formulation}

The optimal power flow is compelled improvement problem requiring the minimization of

$$
f(x, u)
$$

Subject to conditions

$$
\begin{aligned}
& \mathrm{G}_{\mathrm{i}}(\mathrm{x}, \mathrm{u})=0 \ldots \ldots . \mathrm{i}=0,1,2,3, \ldots . \mathrm{m} \text { [equality constrained] }(2) \\
& H_{i}(x, u)=0 \ldots \ldots . i=0,1,2,3, \ldots . . m \text { [inequality constrained] } \\
& u_{\min } \leq u \leq u_{\max } \\
& x_{\min } \leq x \leq x_{\max }
\end{aligned}
$$

The vector $\mathrm{x}$ incorporates every reliant variable which is bus voltage extents and stage points, and additionally the Mvar yield of Generators allocated for bus voltage control and settled parameters as the non-controlled Generator MW and Mvar yields, noncontrolled MW and Mvar loads, settled bus voltages, line parameters, .....

2.1 Objective Function: In SCOPF, the fundamental object is to minimize add up to framework cost keeping the system security. At the point when the load is light, the least expensive generators run firstly, then when it expands, more costly generators work.Figure1 shows input-output curve of a generator. It has a relation between output power in MW and input fuel to the generator in BTU [British Thermal Units per hour].

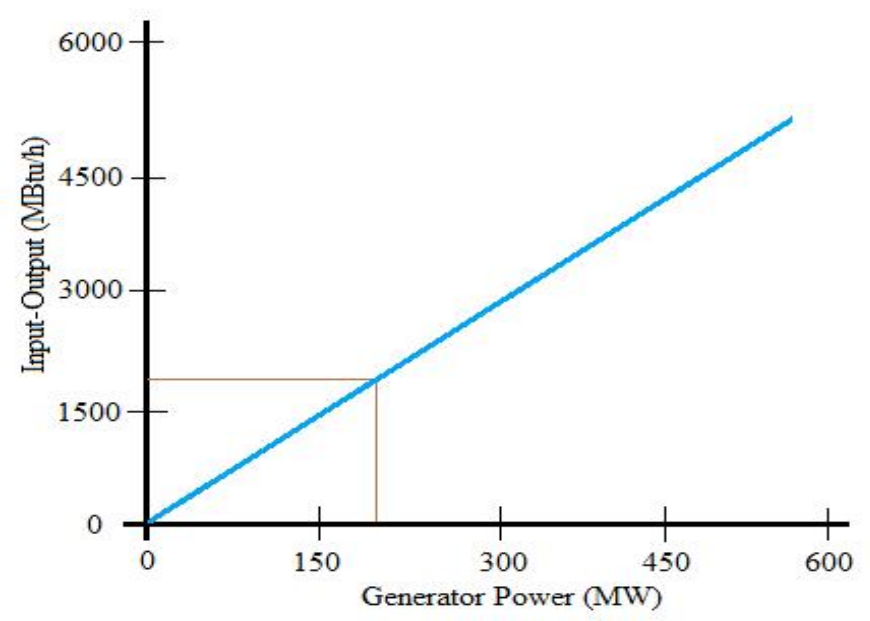

Figure 1.Input-output curve of a generator

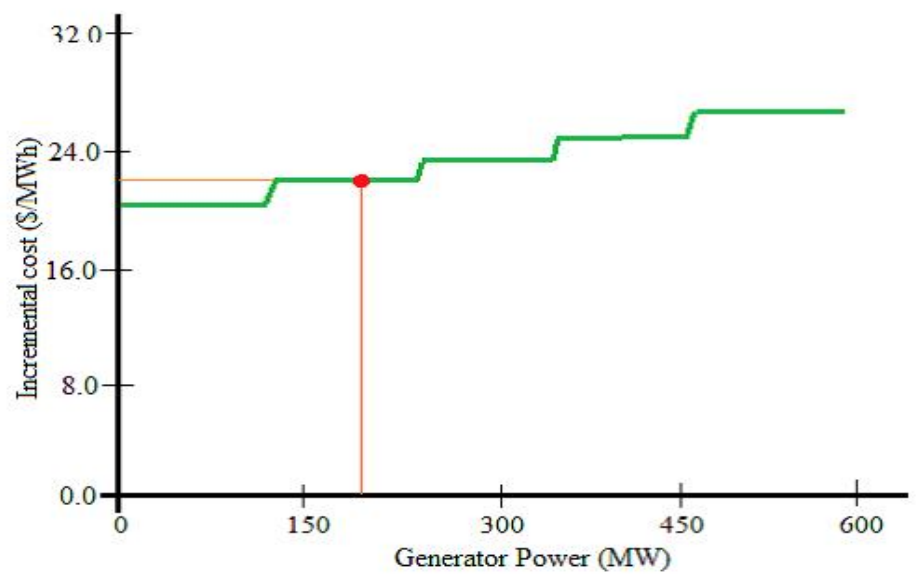

Figure 2.Incremental cost curve

In all practical cases, the cost of generator i can be represented as 


$$
C_{i}=a_{i}+b_{i} p_{i}+c_{i} p_{i}^{2}
$$

where $p_{i}$ is the real output of a generator $i$ and $a_{i}, b_{i}, c_{i}$ are the coefficients of the cost function.

2.2 Control Variables: The estimation of control factors can be straightforwardly conformed to minimize the target work and fulfill the requirements. The control factors can be given as active and reactive power, add up to exchange, control voltage settings, Phase-shifter points, line streams of the transmission and the tap setting of LTC transformer.

2.3 Dependent Variables: The uncontrolled variables of an optimal power flow which are free, within limits as the magnitude and the angle of bus voltage.

2.4 Equality Constraints: The equality constraints of the OPF represent the power framework material science by the power stream conditions and this implies the whole of net infusion of genuine and receptive power at every bus breaks even with zero. This can be accomplished by dynamic and responsive power examination.

$$
\begin{aligned}
& P_{i}=P_{\text {load }}+P_{\text {loss }} \\
& Q_{i}=Q_{\text {load }}+Q_{\text {loss }}
\end{aligned}
$$

Where $P_{i}$ and $Q_{i}$ are the real and reactive power outputs, $P_{\text {load }}$ and $Q_{\text {load }}$ are the real and reactive load power and $P_{\text {loss }}$ and $Q_{\text {loss }}$ are the real and reactive power loss.

2.5 Inequality Constraints: The working security breaking points can minimize the cost work inside these cutoff points

$$
\begin{aligned}
& P_{\text {gimin }} \leq P_{g i} \leq P_{\text {gimax }} \\
& Q_{\text {gimin }} \leq Q_{g i} \leq Q_{\text {gimax }} \\
& \sum P_{\text {gi }}-P_{D}-P_{\text {loss }}=0
\end{aligned}
$$

where $P_{g i}$ is the real power of the generator i in MW, $Q_{g i}$ is the amount of generation in Mvar at generator $i$

The inequality constraints on voltage magnitude $V$ of each PQ bus is $V_{\text {imin }} \leq V_{i} \leq V_{\text {imax }}$ where $V_{\text {imin }}$ and $V_{\text {imax }}$ are the base and most extraordinary estimations of voltages at transport $i$ (Kumar and. Sasikumar, 2015)

\section{Security Constrained OPF}

Security-Constrained OPF (SCOPF) problems are a unique class of OPF problems. It repeats between a base case OPF issue and an arrangement of predefined possibility framework states. To guarantee the security of system, a supposed " $N-1$ criteria" is connected, i.e. there ought to be no infringement after the blackout of any single component in the framework. This leads to the implementation of preventive mode of SCOPF. See that there are c contingencies to be tended to in the SCOPF, and that there are an entire new arrangement of requirements for each of these c possibilities. Watch:

I. Every arrangement of possibility related uniformity requirements is precisely similar to the first arrangement of correspondence imperatives.

II. Every arrangement of possibility related imbalance imperatives is precisely similar to the first arrangement of disparity aside from it compares to the framework with a component expelled and, for branch stream limitations and for voltage magnitudes, the points of confinement will be distinctive.

\section{Optimization Algorithms}

4.1. Genetic Algorithm: It is one of generalized search algorithms which rely on upon the mechanics of hereditary qualities (Devaraj and Yeganarayana, 2005). Genetic Algorithms (GA) consist of a populace of people that are called candidate solutions. They join arrangement assessment with stochastic hereditary administrators to keep up optimally for the goal work.

\subsection{Flower Pollination:}

4.2.1 Pollination

It is characterized as propagation of plants and this happens by gametes union. The gametes are characterized into male which creates the dust grains and female which produces ovules brone. The union happens by exchange the dust to the disgrace. The fertilization of the power is the exchange and testimony of grains from anther to disgrace. The fertilization is a fundamental operation in farming to deliver seeds and organic products. The fertilization is divided into self and Cross Pollination. The self 
pollination happens when the pollination occurs at the same flower or the same plant and this happens when a flower has male and female gametes on the opposite cross pollination happens when dust grains are moved to a blossom from another plant. The procedure of cross fertilization occurs with the assistance of abiotic or biotic operators, for example, creepy crawlies, winged creatures, snails, bats and different creatures as pollinators. Abiotic fertilization is a procedure where the fertilization occurs without contribution of outside specialists. The procedure of fertilization which requires outside pollinators is known as Biotic Pollination to move the dust from the anther to the shame. Bugs assume most imperative part as the pollinators. Creepy crawly Pollination happens in plants with shaded petals a solid scent which pulls in honey bees, moths, scarabs, wasps, ants and butterflies. The bugs are pulled into blossoms because of accessibility of nectar, consumable dust and when creepy crawly sits on the bloom, the dust grains adhere to the body. At the point when the bug visits another blossom, the dust is exchanged to disgrace encouraging fertilization. The fertilization is additionally encouraged by vertebrates like feathered creatures and bats. Blossoms pollinated by bats for the most part have white shaded petals and solid smell. The winged animals more often than not fertilize blooms with red petals and without smell (Balasubramani and Marcus, 2014).

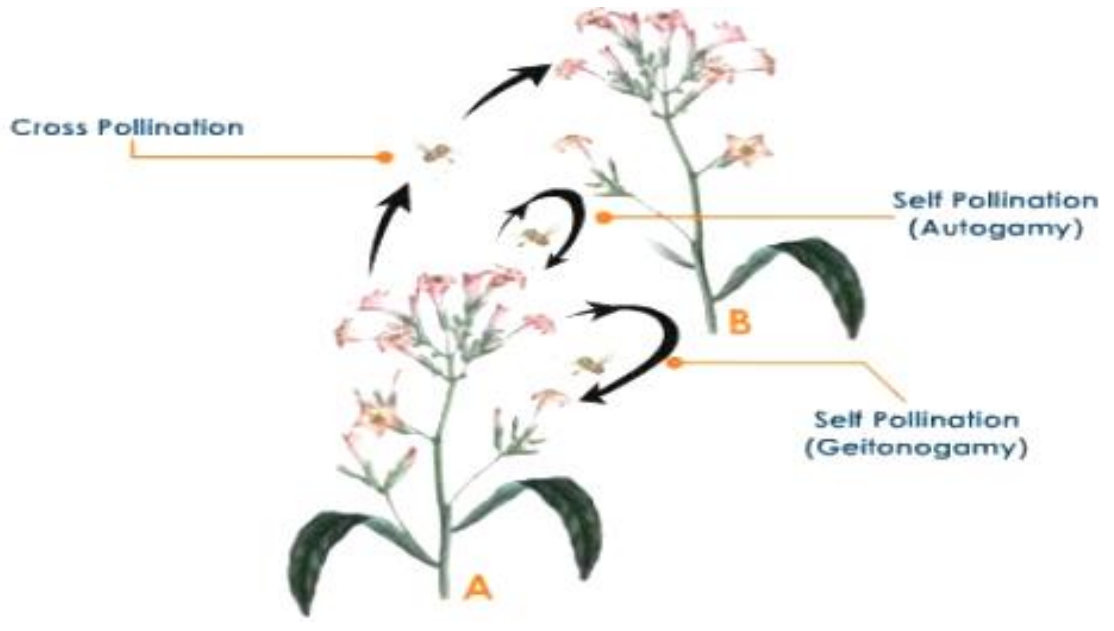

Figure 3.Fertilization

4.2.2 Flower Pollination Algorithm:Blooming plants stream preparations get ready impelled Xin-She Yang to make Flower Pollination Algorithm (FPA) in 2012. For facilitate, the four guidelines given are utilized (Yang, 2013).

1. The procedures of worldwide fertilization incorporate Biotic and cross-fertilization, and pollinators passing on tidy move in a way that asserts to Lévy flights.

2. Abiotic and self-pollination are used in local pollination.

3. Blossom steadiness can be considered as the generation likelihood is relative to the comparability of two blooms included.

4. Neighborhood fertilization and worldwide fertilization are controlled by switch probability $\mathrm{p}$ which has a value between 0 and 1 .

Because of the physical closeness and different variables, for example, wind, nearby fertilization can have a critical part $p$ in the general fertilization exercises. Clearly, in reality, every plant can have different blossoms, and every bloom fix regularly discharge millions and even billions of dust gametes. In any case, for simplicity, we likewise expect that every x plant just has one blossom, and every bloom just create one dust gamete. Along these lines, there is no compelling reason to recognize a dust gamete, a blossom, a plant or answer for an issue. This straightforwardness implies an answer $\mathrm{x}_{\mathrm{i}}$ is identical to a bloom as well as a dust gamete. We can undoubtedly stretch out to different dust gametes for every bloom and numerous blossoms for multi target streamlining issues in future reviews.

From the above examinations, we can plan a blossom in view of calculation, specifically, bloom fertilization calculation (FPA). There are two key strides in this calculation; they are worldwide fertilization and nearby fertilization.In the worldwide fertilization step, blossom dusts are conveyed by pollinators for instance, bugs, and tidies can go over a long detachment since dreadful little creatures can consistently fly and move in an anymore drawn out range. This ensures the fertilization and multiplication of the fittest, and accordingly we speak to the fittest as $\mathrm{g}^{*}$. The main control in addition to bloom steadiness can be formulated as

$$
\mathrm{x}_{\mathrm{i}}^{\mathrm{t}+1}=\mathrm{x}_{\mathrm{i}}^{\mathrm{t}}+\mathrm{L}\left(\mathrm{x}_{\mathrm{i}}^{\mathrm{t}}-\mathrm{g} *\right),
$$

where $\mathrm{x}_{\mathrm{i}}^{\mathrm{t}}$ is the dust $\mathrm{i}$ or arrangement vector $\mathrm{x}_{\mathrm{i}}$ at cycle $\mathrm{t}$, andg*is the present best arrangement found among all arrangements at the present era/emphasis. The parameter $\mathrm{L}$ is the nature of the preparation, which fundamentally is a phase evaluate. Since dreadful 
littleanimals may move over a long partition with various division steps, we can use a L'evy flight to duplicate this trademark productively.That is, we draw $\mathrm{L}>0$ from a Levy conveyance

$$
\mathrm{L} \sim \frac{\lambda \Gamma(\lambda) \sin \left(\frac{\pi \lambda}{2}\right)}{\pi} \frac{1}{\mathrm{~s}^{1+\lambda}}\left(\mathrm{s}>>\mathrm{s}_{0}>0\right)
$$

where $\Gamma(\lambda)$ is the mathematical gamma function, and this formulation is available only in high values of steps $s>0$.

In all our simulations below, we have utilized $\lambda=1.5$. The neighborhood fertilization (Rule 2 ) and bloom consistency can be formulated as

$$
x_{i}^{t+1}=x_{i}^{t}+\in\left(x_{j}^{t}-x_{k}^{t}\right)
$$

where $x_{j}^{t}$ and $x_{k}^{t}$ are dusted from the diverse blossoms of a similar plant animal variety.Scientifically, if $x_{j}^{t}$ and $x_{k}^{t}$ toriginates from comparable species or browsed a comparable masses, this transform into an area discretionary stroll if we draw $\in$ from a uniform conveyance in $[0,1]$. Most blossom fertilization exercises can occur at both nearby and worldwide scale. By and by, adjoining blossom fixes or blooms in the not really far-away neighborhood will probably be pollinated by nearby blossom dusts that those distant. For this, we utilize a switch likelihood (Rule 4) or closeness likelihood p to switch between regular worldwide fertilization to escalate nearby fertilization. Regardless, we can use $\mathrm{p}=0.5$ at first regard and a while later do a parametric survey to find the most fitting parameter extend. From our reenactments, we found that $\mathrm{p}=0.8$ works better for general applications.

\section{Simulation Model}

The examined approaches have been tried by utilizing IEEE-30 bus system as appeared in Figure 4 which comprises of 4 transformers, 6 generators, 41 lines, and two shunt reactors. The aggregate control variables are 16: six unit dynamic power yields, six generator transport voltage sizes, and four transformers tap settings. All generator dynamic power, and generator transport voltages and transformer tap setting are considered as continuous for straightforwardness. The generators cost coefficients of the IEEE 30-test system are given in the Table 1. The limits of variables of the model are given in Table 2 (Test Case Archive).

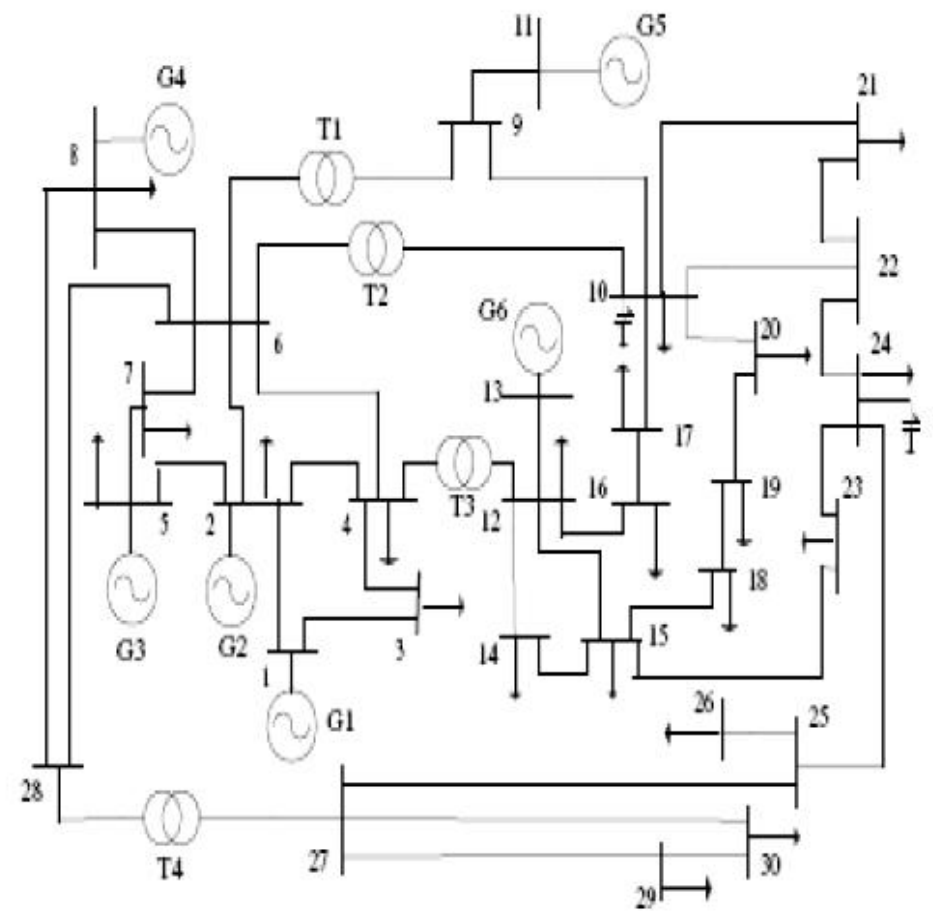

Figure4.IEEE 30-Bus System 
Table 1.Generator cost coefficient of IEEE 30 Bus system

\begin{tabular}{|c|c|c|c|c|c|}
\hline \multirow[t]{2}{*}{ Bus No. } & \multicolumn{2}{|c|}{$\begin{array}{l}\text { Real Power Output Limit } \\
\text { (MW) }\end{array}$} & \multicolumn{3}{|c|}{ Cost Coefficients } \\
\hline & Min & Max & $\bar{m}$ & $\frac{13}{20}$ & \\
\hline 1 & 50 & 200 & 0 & 2.00 & 0.00375 \\
\hline 2 & 20 & 80 & 0 & 1.75 & 0.01750 \\
\hline 5 & 15 & 50 & 0 & 1.00 & 0.06250 \\
\hline 8 & 10 & 35 & 0 & 3.25 & 0.00834 \\
\hline 11 & 10 & 30 & 0 & 3.00 & 0.02500 \\
\hline 13 & 12 & 40 & 0 & 3.00 & 0.02500 \\
\hline
\end{tabular}

Table 2.Limits of Variables for IEEE 30-Bus System

\begin{tabular}{|c|c|c|c|c|}
\hline No & Description & Units & Lower Limits & Upper Limits \\
\hline 1 & Voltage PQ bus & $\mathrm{Pu}$ & 0.95 & 1.05 \\
\hline 2 & Voltage PV bus & $\mathrm{Pu}$ & 0.9 & 1.1 \\
\hline 3 & Transformer Taps & $\mathrm{Pu}$ & 0.9 & 1.1 \\
\hline
\end{tabular}

\section{Results and Discussion}

The 30 bus IEEE model is tried to check the adequacy of the previous techniques. Both with/without applying the possibility examination were tested for checking the system security at each case. The considered techniques are contrasted and different strategies, with respect to quality and examination adequacy. MATLAB language is used.

\subsection{Consequences of a genetic algorithm}

Genetic procedure has been tried on the standard model on two steps, initially the contingencies are not considered and the GA based calculation was connected to locate the ideal scheduling of the power system for the base condition. Minimization of the fuel cost is a must. Generator dynamic power and generator bus voltage were taken as an improved components, were taken as improvement components; besides the GA for handling SCOPF problem is attempted. The perfect estimations of control variables procured are given in Table 3 .

Table 3.Results of genetic algorithm

\begin{tabular}{|c|l|l|l|l|l|l|}
\hline & $\begin{array}{l}\text { Without line } \\
\text { outage (base case) }\end{array}$ & $\begin{array}{l}\text { With line outage } \\
(4-6)\end{array}$ & $\begin{array}{l}\text { With line outage } \\
(2-6)\end{array}$ & $\begin{array}{l}\text { With line } \\
\text { outage (1-2) }\end{array}$ & $\begin{array}{l}\text { With line outage } \\
(1-3)\end{array}$ & $\begin{array}{l}\text { Loss of } \\
\text { generator }\end{array}$ \\
\hline$P_{1}$ & 176.6374 & 172.6048 & 172.8813 & 151.3525 & 168.4838 & 188.5079 \\
\hline$P_{2}$ & 48.7022 & 48.4625 & 47.6091 & 59.2858 & 49.4219 & 51.6303 \\
\hline$P_{5}$ & 21.6967 & 21.2781 & 22.4618 & 24.0334 & 21.7093 & 0 \\
\hline$P_{8}$ & 21.5941 & 25.4855 & 25.6042 & 33.9226 & 27.5947 & 27.2177 \\
\hline$P_{l 1}$ & 11.9399 & 13.3780 & 12.8147 & 16.1131 & 14.5627 & 14.0737 \\
\hline$P_{l 3}$ & 12.1910 & 12.1629 & 12.0940 & 15.0079 & 13.8633 & 13.0268 \\
\hline $\begin{array}{l}\text { Gen.Cost } \\
\$ / h r\end{array}$ & 801.8566 & 806.7550 & 805.9622 & 839.2858 & 815.21 & 832.3776 \\
\hline Loss & 9.3613 & 9.3883 & 10.0650 & 16.3153 & 12.2356 & 11.0565 \\
\hline
\end{tabular}

\subsection{Results of FPA Algorithm}

The recently proposed FPA is applied to IEEE 30 bus system for both with/without performing the contingency analysis.

Scenario 1: Optimization without considering any contingency states

This situation is recommended to exhibit the change of the execution of the standard FPA by giving a subjective and quantitative examination in light of the alteration of the control parameters of the standard FPA without any contingency. This case is considered a base case and also optimized to minimize the standard fuel cost.

Scenario 2: Optimization considering different contingencies 
In this second situation and so as to demonstrate the effect of different cases on the result, line outages at several locations and loss of generator cases are considered.

The results are shown in Table 4

Table 4.Optimal Results of FPA algorithm

\begin{tabular}{|c|l|l|l|l|l|l|}
\hline & $\begin{array}{l}\text { Without line outage } \\
\text { (base case) }\end{array}$ & $\begin{array}{l}\text { With line outage } \\
(4-6)\end{array}$ & $\begin{array}{l}\text { With line outage } \\
(2-6)\end{array}$ & $\begin{array}{l}\text { With line } \\
\text { outage1-2 }\end{array}$ & $\begin{array}{l}\text { With line } \\
\text { outage1-3 }\end{array}$ & $\begin{array}{l}\text { Loss of } \\
\text { generator }\end{array}$ \\
\hline$P_{l}$ & 176.7294 & 172.9495 & 173.7989 & 151.1886 & 168.8781 & 187.9427 \\
\hline$P_{2}$ & 48.8300 & 48.4100 & 47.6720 & 59.2040 & 49.1360 & 51.7400 \\
\hline$P_{5}$ & 21.4750 & 21.6115 & 21.4540 & 24.0580 & 21.8775 & 0 \\
\hline$P_{8}$ & 21.6475 & 25.6100 & 25.0825 & 33.9500 & 27.6750 & 27.4925 \\
\hline$P_{l 1}$ & 12.0940 & 13.1700 & 13.3280 & 16.3840 & 14.3140 & 14.0940 \\
\hline$P_{l 3}$ & 12.0000 & 12.0000 & 12.2296 & 14.8980 & 13.9236 & 13.1480 \\
\hline $\begin{array}{l}\text { Gen.Cost } \\
\$ / h r\end{array}$ & 801.8436 & 806.7213 & 805.8811 & 839.2833 & 815.1970 & 832.3756 \\
\hline Loss & 9.3753 & 10.3510 & 10.1650 & 16.2826 & 12.4042 & 11.0172 \\
\hline
\end{tabular}

From Table 4, we can see that the best cost is achieved by a number of progressive trials, the best aggregate cost accomplished is $801.8436 \$ / \mathrm{h}$ in the base case. To get the best solutions, a medium number of iterations should be done. With the end goal of checking the effectiveness of the discussed technique, we made a correlation of our calculation with others contending OPF calculations. Table 5 demonstrates the best results of various techniques. Test of factual outcomes is given to demonstrate the capacity of the proposed procedure to accomplish the neighborhood look undertaking. By modifying the cutoff points of control factors amid trials, this permits the lessening of the number of cycles and decreases the execution time, the best aggregate fuel cost discovered considering the base case is 801.8436 , and this esteem is exceptionally focused and superior to anything different strategies referred to in countless papers.

Table 5.Comparison of total cost(without line outage)

\begin{tabular}{|c|l|l|l|l|l|l|}
\hline $\begin{array}{l}\text { Power } \\
\text { output(MW) }\end{array}$ & GA & FPA & $\begin{array}{l}\text { GA } \\
\text { (Banu and } \\
\text { Devaraj,2009) }\end{array}$ & $\begin{array}{l}\text { DE } \\
\text { (Priyadarshini } \\
\text { and Babu,2013) }\end{array}$ & $\begin{array}{l}\text { BAT } \\
\text { (Sakthivel et } \\
\text { al.,2013) }\end{array}$ & $\begin{array}{l}\text { IPSO } \\
\text { (Vahedi. et al., } \\
\text { 2010) }\end{array}$ \\
\hline$P_{1}$ & 176.6374 & 176.7294 & 173.6 & 175.7754 & 176.27888 & 198.69 \\
\hline$P_{2}$ & 48.7022 & 48.8300 & 50.2 & 49.1716 & 49.0012 & 36.16 \\
\hline$P_{5}$ & 21.6967 & 21.4750 & 21.8 & 21.7542 & 21.3870 & 17.64 \\
\hline$P_{8}$ & 21.5941 & 21.6475 & 23.8 & 21.9092 & 22.4669 & 11.45 \\
\hline$P_{11}$ & 11.9399 & 12.0940 & 10.8 & 12.2328 & 12.2314 & 12.15 \\
\hline$P_{13}$ & 12.1910 & 12.0000 & 12.3 & 12.1140 & 11.5256 & 11.87 \\
\hline Gen.Cost $\$ / h r$ & 801.8566 & 801.8436 & 802.32 & 802.7683 & 802.3919 & 827.13 \\
\hline Loss & 9.3613 & 9.3753 & - & 9.5572 & 9.49098 & 9.12 \\
\hline
\end{tabular}

Table 6 shows the comparison between the proposed algorithm with other recent algorithms in contingency cases with the same fitness function and control variables

Table 6. Comparison of SCOPF results (considering contingency cases)

\begin{tabular}{|c|c|c|c|}
\hline Approach & Line outage & cost & Losses \\
\hline Genetic & \multirow[b]{3}{*}{$2-6$} & 805.962 & 10.0650 \\
\hline FPA & & 805.8811 & 10.1650 \\
\hline $\begin{array}{c}\text { Differential } \\
\text { evolution(Priyadarshiniand } \\
\text { babu,2013) }\end{array}$ & & 807.8546 & 10.8358 \\
\hline Genetic & \multirow{3}{*}{$1-2$} & 839.2858 & 16.3153 \\
\hline FPA & & 839.2833 & 16.2826 \\
\hline MI-BFA (Vahedi.et al., 2010) & & 878.24 & - \\
\hline Genetic algorithm & \multirow{3}{*}{$1-3$} & 815.21 & 12.2356 \\
\hline FPA & & 815.1970 & 12.4042 \\
\hline BPSO(Polprasert et al.,2014) & & 1217.6 & - \\
\hline
\end{tabular}


From the above results, we can summarize that:

- The meeting qualities of the FPA still require an expansive number of steps to accomplish the best solution.

- A relative review in term of arrangement quality is delineated in Tables 5 and 6, as should be obvious; the examined technique gives preferred outcomes over different late standard and hybrid strategies.

- Each system has its own particular points of interest and disadvantages, in all actuality it relies on upon the capacities, the picked steps, parameters and number of trials.

The test comes about on the IEEE 30-bus model show that the examined SCOPF strategies can discover preferred arrangements over alternate techniques in a speedier merging.

\section{Conclusion}

In this paper, an effective FPA algorithm has been introduced, adapted and successfully applied to improve the solution of security constrained optimal power flow considering critical objective function. The main contribution of the discussed methodology is minimizing the total generation cost as well as enhancing transmission security and bus voltage profile under typical or unexpected states. The performance of the introduced FPA has been tested with a standard test power system, IEEE 30 bus. It is observed that the proposed approach is capable to reduce the total fuel cost at normal and critical states compared to the old methods.

\section{Nomenclature \\ SCOPF security constrained optimal power flow \\ FPA flower pollination algorithm \\ OPF optimal powerflow}

\section{References}

AbidoM, 2002a, Optimal power flow using tabu search algorithm, Electric Power Components and Systems, pp. 469-483.

AbidoM, 2002b, Optimal power flow using particle swarm optimization, Electrical Power \& Energy Systems, Vol. 24, pp. 563571.

Alsac O.,and Scott B., 1973, Optimal load flow with steady state security, IEEE Transaction. PAS-1973, pp. 745-751.

Balasubramani K., Marcus K., 2014, A study on flower pollination algorithm and its applications, International Journal of Application or Innovation in Engineering \& Management, Vol. 3, No. 11, pp.230-235.

BanuR., Devaraj D., 2009, Enhanced genetic algorithm approach for security constrained optimal power flow including FACTS devices, International Journal of Electrical Power and Energy Systems Engineering, Vol. 2, No. 1, pp. 33-38.

Capitanescua F., and Wehenkel L., 2013, Experiments with the interior-point method for solving large scale optimal power flow problems, Electric Power Systems Research, Vol. 95, pp. 276-283.

Devaraj D., and Yeganarayana B., 2005, Genetic algorithm based optimal power flow for security enhancement, IEE Proceedings on Generation Transmission and Distribution, Vol. 152, No. 6, pp. 899-905

Gaing Z., and ChangR., 2006, Security-constrained optimal power flow by mixed-integer genetic algorithm with arithmetic operators,IEEE Power Engineering Society Meeting,pp.1-8.

Kumar D. and Sasikumar G, 2015, Security constrained optimal power flow using benders cut principle, International Journal of Control Theory and Applications, Vol.8, No.1, pp.264-276.

Lima F.G.M., Galiana F.D., Kockar I., Munoz J.2003, Phase shifter placement in large -scale systems via mixed integer programming, IEEE Transactions on Power Systems, Vol. 18, No. 3, pp.1029-1034.

Mithun M., Muthyala, S. and Maheswarapu S.2010, Security constraint optimal power flow (SCOPF) -A comprehensive survey, International Journal of Computer Applications, Vol. 11, No.6, pp. 42-52.

Niu.M., WanC., 2014, A review on applications of heuristic optimization algorithms for optimal power flow in modernpowersystems, Journal of Modern Power System and Clean Energy,pp.289-297.

Paranjothi S. and AnburajaK., 2002, Optimal power flow using refined genetic algorithm, Electric Power Components and Systems, Vol. 30, pp. 1055-1063.

Polprasert J., Ongsakul W. and Ngoc D., 2014, Security constrained optimal power flow using self-organizing hierarchical PSO with time-varying acceleration coefficients, Global Journal of Technology \& Optimization, Vol. 5, No. 1,pp.1-6.

Power Systems Test Case Archive. Available [Online] at: http://www.ee.washington.edu/research/pstca/

Priyadarshini M. and Murali Babu B., 2013, Differential evolution algorithm for security constrained optimal power flow, International Journal of Engineering and Advanced Technology, Vol. 2, No. 5, pp.352-356. 
Sakthivel S., Natarajan R., Gurusamy P., 2013, Application of bat optimization algorithm for economic load dispatch considering valve point effects, International Journal of Computer Applications, Vol. 67, No.11, pp. 35-39.

Salgado R., Braneller A., Aitchison P., 1990, Optimal power flow solutions using the gradient projection method. II. Modelling of the power system equations, IEE Proceedings C - Generation, Transmission and Distribution, Vol. 137, No. 6, pp. 429-435.

Singh S., Verma K.S., 2012, Optimal power flow using genetic algorithm and particle swarm optimization, IOSR Journalof Engineering, Vol. 2, No. 1, pp. 46-49.

Sivasubramani S., and Swarup K., 2011, 'Multi-objective harmony search algorithm for optimal power flow problem, International Journal on Electrical Power and Energy Systems, Vol. 33, No. 3, pp. 745-752.

Tinney W., and Hart C.,1967, Power flow solution by Newton's method, IEEE Transactions on Power Apparatus and Systems, Vol. PAS-86, No. 11,pp. 1449-1460.

TuaimahF., Meteb M., 2014, A linear programming method based optimal power flow problem for Iraqi extra high voltage grid (EHV), Journal of Engineering, Vol. 20, pp. 23-35.

Turkay B. and CabadagR., 2013, Optimal power flow solution using particle swarm optimization algorithm, Eurocon IEEE,pp. 1418-1424.

Vahedi H., Hosseini S., and Noroozian R., 2010, Bacterial foraging algorithm for security constrained optimal power flow, 7th International Conference on the European Energy Market,pp.1-6.

Walters. D. C. and Sheble G. B., 1993, Genetic algorithm solution of economic dispatch with valve point loading, IEEE Transactions on Power Systems, Vol. 8, No. 3, pp. 1325-1332.

Yang X., 2013, Flower pollination algorithm for global optimization, Department of Engineering, University of Cambridge, England.

\section{Biographical notes}

Almoataz Y. Abdelaziz received the B.Sc. and M.Sc. degrees in electrical engineering from Ain Shams University, Egypt, in 1985 and 1990 , respectively, and the Ph.D. degree in electrical engineering according to the channel system between Ain Shams University, Egypt, and Brunel University, U.K., in 1996. He is currently a Professor of Electrical Power Engineering at Ain Shams University. Dr. Abdelaziz is the chair of IEEE Education Society chapter in Egypt, Senior Editor of Ain Shams Engineering Journal, editor of Electric Power Components \& Systems Journal, editorial board member, associate editor and editorial advisory board member of several international journals and conferences. He is also a member in IET and the Egyptian Sub-Committees of IEC and CIGRE'. He has been awarded many prizes for distinct researches and for international publishing from Ain Shams University, Egypt. He has authored or coauthored more than 300 refereed journal and conference papers in his research areas which include the applications of artificial intelligence, evolutionary and heuristic optimization techniques to power system operation, planning, and control.

M.Ezzat Abdelrahman received the B.Sc. and M.Sc, and Ph.D. degrees in electrical engineering from Faculty of Engineering, Ain Shams University, Cairo, Egypt in 2001, 2007 and 2012 respectively. He is currently working as an assistant professor at the electric power and machines department, Ain Shams University, Cairo, Egypt. His field of research includes power system analysis, protection and planning. He is also interested in the researches including artificial intelligence tools.

Reham H.Salem was born in Cairo, Egypt, on December 1, 1985. She received the B.Sc. and M. Sc. degrees in electrical engineering from Ain Shams University, Egypt in 2007, 2013 respectively. Currently she is working at the Higher Institute of Engineering and Technology, Fifth Settlement. Her research interests include applications of optimization techniques to electrical engineering problems and power system reconfiguration.

Received May 2017

Accepted June 2017

Final acceptance in revised form June 2017 